\title{
Atmospheric Transport and Bulk Deposition of Organochlorine Compounds at Leigongshan Nature Reserve in Southwestern China
}

\author{
Jiayi Zhou ${ }^{1,2}$, Libin Liu ${ }^{3}$, Xin $\mathrm{Xu}^{1}$, Yongfu Yu ${ }^{4}$, Yang $\mathrm{Li}^{4}$, Haiyan Zhang ${ }^{5}$, Yue $\mathrm{Xu}^{{ }^{*}}$ \\ ${ }^{I}$ State Key Laboratory of Environmental Geochemistry, Institute of Geochemistry, Chinese Academy of Sciences, Guiyang \\ 550002, China \\ ${ }^{2}$ State Key Laboratory of Organic Geochemistry, Guangzhou Institute of Geochemistry, Chinese Academy of Sciences, \\ Guangzhou 510640, China \\ ${ }^{3}$ College of Chemistry and Life Sciences, Zhejiang Normal University, Jinhua 321004, China \\ ${ }^{4}$ Leigong Mountain National Nature Reserve Administration, Leishan 557100, China \\ ${ }^{5}$ The Johns Hopkins University-Nanjing University Center for Chinese and American Studies, Nanjing University, \\ Nanjing, 210093, China
}

\begin{abstract}
Atmospheric and bulk deposition samples collected at Leigongshan Nature Reserve (LNR) were analyzed to explore the status, transport, and deposition of atmospheric pollution - specifically, organochlorine compounds - in the foggy mountains of southwestern China. Prohibiting and restricting persistent organic pollutants in the surrounding areas has led to a decline in organochlorine pesticides and polychlorinated biphenyls (PCBs), but not hexachlorobenzene (HCB), in the air. Wet deposition is a factor that strongly influences the atmospheric input at LNR. Despite the relatively low atmospheric concentration levels of hexachlorocyclohexanes (HCHs) and $\mathrm{HCB}$, heavy precipitation can increase the deposition of these compounds in summer. The airborne HCHs exhibited a "bimodal" pattern, with higher concentrations in spring and autumn and lower concentrations in summer, the latter of which are results of high surface input into the ground along the transport routes of these compounds from South and Southeast Asia to southwestern China. The HCB at LNR mainly originates in mainland China. The deposition fluxes are influenced by the enhanced washout of atmospheric particles in the rainy season and increased particle-associated content in winter. The potential sources of $o, p^{\prime}$-DDT, $p, p^{\prime}$-DDT, and PCBs are distributed widely over low-latitude western areas and eastern China. Atmospheric transport and deposition in spring and summer contribute a significant proportion of the total fluxes annually when air masses originating in Southeast Asia arrive, increasing rainfall at LNR. The foggy local weather may also enhance this deposition, eventually leading to the accumulation of pollutants at LNR.
\end{abstract}

Keywords: Air transport; Bulk deposition; Foggy mountain; OCPs; PCBs.

\section{INTRODUCTION}

Persistent organic pollutants (POPs) are a group of toxic, persistent, and bioaccumulative chemicals prohibited or restricted by a series of multilateral environmental agreements, such as the Stockholm Convention, the Basel Convention, and the Rotterdam Convention. Atmospheric transport and deposition are considered major pathways for the redistribution of these pollutants to pristine environments. To evaluate the air quality degeneration associated with POPs, air monitoring networks, such as the NJADN in

\footnotetext{
* Corresponding author.

Tel.: 86-0851-8439-6941

E-mail address: xu-yue@mail.gyig.ac.cn
}

New Jersey (Van Ry et al., 2002; Gioia et al., 2005), IDAN for the Great Lakes (Hoff et al., 1996; Melymuk et al., 2011), and the AMAP for the Arctic (Hung et al., 2016), have been established for extensive monitoring. Localscale observations have also been conducted in Germany (Bruckmann et al., 2013), Sweden (Bergknut et al., 2011), and other European countries (Carrera et al., 2002; Arellano et al., 2015; Jakobi et al., 2015). Relevant research has also been conducted in China (Wong et al., 2004; Yang et al., 2012; Liu et al., 2013; Guo et al., 2017), but most study data have been obtained from urban or suburban areas relatively close to the pollution sources. These observations provide extensive historical and current information on variations in air quality, which is useful to assess the effectiveness of national and international chemical control initiatives (Hung et al., 2016).

To effectively implement the Stockholm Convention, 
the Chinese government is taking measures to reduce and eliminate pesticide POPs, polychlorinated biphenyls (PCBs), and dioxins (SEPAC, 2007). Primary emissions of pesticides and PCBs generally show a decreasing trend in China (Wang et al., 2005; Cui et al., 2015). However, current application or emission still dominates the air in low latitude areas, such as Vietnam, India, or the Bay of Bengal. Distinct seasonal changes in prevailing wind directions and precipitation patterns caused by the Indian monsoons may result in atmospheric transport from those sources to pristine areas in western China such as the Tibetan Plateau (Sheng et al., 2013). Moreover, the emission of historical residues of POPs in eastern China could also influence relatively clean regions in the west. A numerical study identified the influences of pollution sources in eastern China and India on sink accumulation in southwestern China (Xu et al., 2013). Therefore, monitoring at the receptor sites in western China is essential to evaluate the pollution status and the transport and transfer processes.

In this paper, concurrent measurements of organochlorine pesticides (OCPs) and PCBs in both air and bulk deposition were performed at a mountaintop in Leigongshan Nature Reserve (LNR) of Guizhou Province, which is an important habitat for rare plant and animal species. Compared with the surrounding provinces, the historical usage of OCPs and PCBs is the lowest in Guizhou (Wang et al., 2005). From a climatological perspective, this nature reserve, located within $100^{\circ}$ and $110^{\circ} \mathrm{E}$, delineates the South Asian and East Asian monsoon regions (Wang et al., 2003); it thus has the potential to receive airborne pollutants transported from the regions lying to its east and west. A numerical simulation of the environmental fate of $\alpha-\mathrm{HCH}$, performed after $\mathrm{HCH}$ restrictions were promulgated in Asia, suggested a potential sink in the surrounding areas (Xu et al., 2013). Atmospheric observations at LNR may reveal the background air quality status in southwestern China and the possible atmospheric transport routes. Bulk deposition together with air monitoring can be used to assess the atmospheric loadings and the link between transport and deposition.

\section{METHODS}

\section{Sample Collection and Site Description}

Starting from January 6, 2016, atmospheric and deposition samples were collected for 1 year at the top of Leigongshan Mountain $\left(26.389^{\circ} \mathrm{N}, 108.205^{\circ} \mathrm{E} ; 2178 \mathrm{~m}\right.$ above sea level), which is within LNR (Fig. S1). Located in Leishan County, Guizhou Province, this nature reserve covers an area of 47,300 ha, with $88 \%$ forest coverage. It is a temperate area with mild temperature, abundant rainfall, and vertical climate variation. The annual average temperature at the top of the mountain is approximately $9.4^{\circ} \mathrm{C}$, and the annual precipitation is $1300 \mathrm{~mm}$. The monthly average temperature and precipitation are plotted in Fig. S2. The mountain is foggy year-round, with more than 300 foggy days each year. Because the mountaintop is characterized by dense fog and light drizzle, long-term dry deposition samples are difficult to obtain; thus, bulk atmospheric deposition samples were collected in this study.

Using a modified Anderson-type high-volume air sampler operated at a rate of $430 \mathrm{~m}^{3}$ day $^{-1}, 24-\mathrm{h}$ air samples were collected once every 6 days. Atmospheric particulate and gaseous samples were collected using quartz microfiber filters (QFFs) $(20.3 \times 25.4 \mathrm{~cm}$, Grade GF/A) and polyurethane foam (PUF) plugs $(8.0 \mathrm{~cm}$ (length) $\times 6.25 \mathrm{~cm}$ (diameter) $)$, respectively. Atmospheric bulk deposition samples were collected using stainless-steel funnels mounted $0.5 \mathrm{~m}$ above the ground. The continuous samples obtained within each month were combined, and the total monthly rainfall was measured using a calibrated jar. Deposition samples were filtered using glass microfiber filters (GMFs) (diameter $=4.7 \mathrm{~cm}$, Grade $\mathrm{GF} / \mathrm{F}$ ) and passed through a chromatographic column containing a mixture of XAD-2 and XAD-4 (1:1) resin. Before sampling, the QFFs and GMFs were baked at $400^{\circ} \mathrm{C}$ for $4 \mathrm{~h}$. The weights of the filters were measured before and after sampling. The PUFs and resin were precleaned twice in a Soxhlet apparatus by using acetone and dichloromethane (DCM), and these materials were kept frozen until use. The stainless-steel funnels for deposition sampling were cleaned using ethanol and DCM. The deposition samples were analyzed after storage, transportation, and filtration. The pollutants in the dissolved and particulate phases do not necessarily reflect the original phase partitioning because submicron particles might have passed through the $0.7-\mu \mathrm{m}$ filter pores into the dissolved phase. Deposition was recorded as the sum of the target compound in the GMF and resin samples. Filters (QFFs and GMFs), PUFs, and resin columns were wrapped with clean aluminum foil, sealed in Teflon bags, and stored at $-18^{\circ} \mathrm{C}$ until analysis.

\section{Analytical Procedures}

Before laboratory analysis, QFFs and PUFs were spiked with internal standards, including 2,4,5,6-tetrachloro- $m$ xylene (TCmX), PCB-30, ${ }^{13} \mathrm{C}-\mathrm{PCB}-28,{ }^{13} \mathrm{C}-\mathrm{PCB}-52$, ${ }^{13} \mathrm{C}-\mathrm{PCB}-101,{ }^{13} \mathrm{C}-\mathrm{PCB}-118,{ }^{13} \mathrm{C}-\mathrm{PCB}-153,{ }^{13} \mathrm{C}-\mathrm{PCB}-138$, ${ }^{13} \mathrm{C}-\mathrm{PCB}-180$, and PCB-209 as recovery surrogates, after which they were separately Soxhlet-extracted using DCM for $48 \mathrm{~h}$. Deposition samples were also spiked with the same standards, filtered by GMFs and absorbed by XAD resin, and then Soxhlet-extracted using DCM for $48 \mathrm{~h}$. The extracts were concentrated to a volume of $1 \mathrm{~mL}$ by using a rotary evaporator and solvent-exchanged into hexane. Extract purification was performed using an alumina/silica column containing anhydrous sodium sulfate, $50 \%$ sulfuric acid silica, neutral silica gel, and neutral alumina. The purified extracts were evaporated to approximately $100 \mu \mathrm{L}$ under low nitrogen flow, following which $20 \mu \mathrm{L}$ of dodecane was added. Samples were concentrated to the final volume of $20 \mu \mathrm{L}$. Then, ${ }^{13} \mathrm{C}$-PCB-141 was added to each sample as an internal standard for analyzing OCPs and PCBs.

In total, 47 chromatographic peaks corresponding to 32 PCB congeners (PCB-8, -28, -37, -44, -49, -52, -60, -66, $-70,-74,-77,-82,-87,-99,-101,-105,-114,-118,-126$, $-128,-138,-153,-156,-158,-166,-169,-170,-179,-180$, $-183,-187$, and -189 ) and 11 OCP compounds (HCB, $\alpha-\mathrm{HCH}$, $\beta-\mathrm{HCH}, \gamma-\mathrm{HCH}, \delta-\mathrm{HCH}$, and $o, p^{\prime}-$ and $p, p^{\prime}-\mathrm{DDE},-\mathrm{DDD}$ 
and -DDT) were analyzed. The target compounds were detected and measured using an Agilent 7890/7000 GCMS/MS in multiple reaction monitoring (MRM) mode with a capillary column (length $=50 \mathrm{~m}, \mathrm{ID}=0.25 \mathrm{~mm}$, thickness $=0.25 \mu \mathrm{m}$; CP-Sil $8 \mathrm{CB}$, Varian). Sample $(1 \mu \mathrm{L})$ was injected in splitless mode. The initial GC oven temperature was set at $80^{\circ} \mathrm{C}$ for $0.5 \mathrm{~min}$, raised to $160^{\circ} \mathrm{C}$ at a rate of $20^{\circ} \mathrm{C} \mathrm{min}{ }^{-1}$, to $240^{\circ} \mathrm{C}$ at a rate of $4^{\circ} \mathrm{C} \mathrm{min}{ }^{-1}$, to $295^{\circ} \mathrm{C}$ at $10^{\circ} \mathrm{C} \mathrm{m^{-1 }}$, and finally held for $10 \mathrm{~min}$. High purity helium was used as the carrier gas, with a flow rate of $1.0 \mathrm{~mL} \mathrm{~min}$. The instrumental settings of the GCMS/MS were the same as those described by Huang et al. (2014) and Zheng et al. (2014).

\section{$Q A / Q C$}

The sampling and experimental procedures were controlled through tests of breakthrough, recovery, lab blanks, and field blanks. A breakthrough test was performed by placing a smaller PUF plug below the main PUF in the sampler. The smaller PUF trapped only 0-3\% of the compounds targeted in this study. Lab blanks were precleaned QFFs, GMFs, PUFs, and XAD resin. Filed blanks for collecting air samples were precleaned QFFs and PUFs exposed to ambient air for approximately $5 \mathrm{~min}$, whereas those for the deposition samples were precleaned GMFs and XAD resins exposed to purified water at the sampling site. The lab and field blanks were stored and analyzed along with each batch of samples.

To determine the analytical recovery efficiencies, all collected samples were spiked with surrogates. The average recoveries of TCmX, PCB-30, ${ }^{13} \mathrm{C}-\mathrm{PCB}-28,{ }^{13} \mathrm{C}-\mathrm{PCB}-52$, ${ }^{13} \mathrm{C}-\mathrm{PCB}-101,{ }^{13} \mathrm{C}-\mathrm{PCB}-118,{ }^{13} \mathrm{C}-\mathrm{PCB}-153,{ }^{13} \mathrm{C}-\mathrm{PCB}-138$, ${ }^{13} \mathrm{C}-\mathrm{PCB}-180$, and PCB-209 were $60 \pm 9.6 \%, 70 \pm 8.8 \%$, $63 \pm 4.1 \%, 72 \pm 5.9 \%, 75 \pm 4.7 \%, 74 \pm 4.4 \%, 79 \pm 8.3 \%$, $82 \pm 9.6 \%, 87 \pm 13 \%$, and $96 \pm 14 \%$, respectively. Because the recoveries were relatively stable, the data were not recovery corrected. The instrumental stability of GCMS/MS was checked daily by using two series of OCP and PCB standards, and a relative standard deviation within $\pm 15 \%$ was ensured. The instrumental detection limits (IDLs) were integrated where the signal-to-noise ratio was 3 in the chromatograms of samples. The method detection limits (MDLs) were derived from the mean concentrations of the target compounds of the field blanks, in units of mass plus three standard deviations $(3 \sigma)$. Target OCPs were not detected in field blanks of air particle samples. Target compounds in the field blanks ranged from less than the IDL to $0.17 \mathrm{ng}$ for the other matrixes employed in this study. For compounds less than the IDL in the field blanks, the MDL was defined as the IDL. The MDLs of the target PCBs and OCPs ranged from 0.002 to $1.1 \mathrm{pg} \mathrm{m}^{-3}$ for the air samples and from 0.05 to $2.5 \mathrm{pg} \mathrm{L}^{-1}$ for the water samples (Table S1). The quantities of compounds in the samples were blank-corrected.

\section{Back-trajectory and Potential Source Contribution Function Analysis}

Air mass movement was estimated through trajectory analysis. For the sampling days, 5-day air parcel back- trajectories were calculated at 6-h intervals using the Hybrid-Single Particle Integrated Trajectory (HYSPLIT 4.8) model developed by the National Oceanic and Atmospheric Administration (NOAA) Air Resource Laboratory (http://www.arl.noaa.gov/HYSPLIT.php). Each trajectory was estimated at $500 \mathrm{~m}$ above ground level. Fig. S3 shows the monthly precipitation data from the Global Precipitation Climatology Centre provided by NOAA as well as the prevailing air mass backward trajectories clustered using HYSPLIT 4.8.

Potential source contribution function (PSCF) analysis (Hafner and Hites, 2003; Hoh and Hites, 2004) was employed to illustrate the spatial distribution of the potential sources. Back-trajectory lines are a series of points representing the position of the modelled air mass at each hour. All the hourly points in the trajectories generated by HYSPLIT 4.8 were sorted into $1^{\circ}$ (latitude) $\times 1^{\circ}$ (longitude) cells. Accordingly, the PSCF of each grid is defined as follows:

PSCF $=\mathrm{N}_{\text {high }} / \mathrm{N}_{\text {all }}$

where $\mathrm{N}_{\text {high }}$ is the number of endpoints corresponding to the measured pollutant concentrations higher than a given criterion threshold. In this study, all trajectories corresponding to the chemical concentrations $>$ average $+0.125 \times$ standard deviations were selected. $\mathrm{N}_{\text {all }}$ is the total number of endpoints falling in the grid cell. To avoid numerical uncertainties, grid cells with $\mathrm{N}_{\text {all }}<10$ were excluded. The calculated PSCF represents the probability of a given cell being a potential source region for a specific observatory, rather than the strength of sources for a large region.

\section{Deposition Estimation}

Deposition fluxes were calculated assuming equilibrium status for the compounds in the air and the rain. The predicted deposition fluxes are the sum of the dry particle deposition $\left(\mathrm{F}_{\mathrm{dry}}\right)$, the washout of the particle phase $\left(\mathrm{F}_{\text {part }}\right)$, and the dissolved phase $\left(\mathrm{F}_{\text {diss }}\right)$ :

$$
\begin{aligned}
& F_{d r y}=C_{\text {part }} \times V_{d} \\
& F_{\text {part }}=C_{\text {part }} \times \text { rain } \\
& F_{\text {diss }}=C_{\text {rain }} \times \text { rain }=C_{\text {gas }} \times \text { rain } \times R \times T / H
\end{aligned}
$$

where $\mathrm{C}_{\text {part }}, \mathrm{C}_{\text {gas }}$, and $\mathrm{C}_{\text {rain }}$ are the concentrations of the target compounds in the atmospheric particle phase, gaseous phase, and rainfall, respectively. $\mathrm{V}_{\mathrm{d}}$ is the reported dry deposition rates $\left(0.2 \mathrm{~cm} \mathrm{~s}^{-1}\right)$ (Hillery et al., 1998; Miller et al., 2001), rain is the precipitation intensity $\left(\mathrm{m} \mathrm{month}^{-1}\right)$, $\mathrm{R}$ is the gas constant $\left(8.314 \mathrm{~Pa} \mathrm{~m}^{3} \mathrm{~mol}^{-1} \mathrm{~K}^{-1}\right), \mathrm{T}$ is the temperature, and $\mathrm{H}$ is the temperature-dependent Henry's law constant (Mackay et al., 2006).

\section{RESULTS AND DISCUSSION}

\section{Pollution Levels}

Atmospheric OCPs and PCBs were mainly distributed in the gas phase of the air. The detection rate of the targeted 
11 OCPs and 11 PCBs, including HCB, HCHs, DDTs, and PCB-8, -28, -37, -44, -52, -60, -66, -70, -74, -99, and -101, were $>80 \%$ in the gas phase samples. Detection rates in the particle phase were generally $<50 \%$; hence, the air concentration results were calculated based on the total concentration. The average air concentration levels of OCPs and PCBs are summarized in Table S2. For compounds with concentration below the MDL, the mean concentration levels were calculated by assuming "not detected" data as equal to 1/3 MDL. Atmospheric OCP and PCB contamination at LNR is comparable with that recently reported for other regional background sites in China and worldwide (Table S2). The annual average concentrations of HCHs at LNR compare favorably with those at other background sites in China (Gong et al., 2017; Zhan et al., 2017), the Arctic (Bossi et al., 2016), and Sweden (Bidleman et al., 2017), whereas DDT levels were lower than those at other sites in China (Sheng et al., 2013; Gong et al., 2017; Zhan et al., 2017) and comparable with those at polar regions (Bossi et al., 2016; Bidleman et al., 2017) and European high Alpine stations (Kirchner et al., 2016). The mean HCB concentration at LNR was lower than that reported in other studies, except for the Tibetan Plateau (Sheng et al., 2013; Gong et al., 2017). Total PCB concentrations $\left(\Sigma_{32} \mathrm{PCB}\right)$ ranged from 4.2 to $35 \mathrm{pg} \mathrm{m}^{-3}$, with an average of $15 \pm 7.2 \mathrm{pg} \mathrm{m}^{-3}$. The average contribution of di-, tri-, tetra-, penta-, hexa-, and hepta-CBs were $17 \%$, $35 \%, 37 \%, 7.9 \%, 1.9 \%$, and $0.7 \%$, respectively. The concentrations of seven indicator PCBs - namely PCB-28, $-52,-101,-118,-138,-153$, and -180 - were compared with those reported in the literature. The average concentration levels were relatively high but lower than those found in central China (Zhan et al., 2017). The atmospheric concentrations of OCPs and PCBs at a background site in Guizhou Province were evaluated in a passive air sampling (PAS) campaign conducted in 2004 (Jaward et al., 2005); POPs sequestered through PAS were converted to air concentrations and are listed in Table S2. Compared with data in 2004, air concentrations of DDTs and highmolecular-weight PCBs reduced to low levels, whereas those of more volatile compounds, such as HCB and lowmolecular-weight PCBs, either showed a slight decline or remained at the same levels.

The deposition concentrations at LNR were in the range reported at other remote sites. Volume weighted mean $\left(\mathrm{ng} \mathrm{L}^{-1}\right)$ concentrations in the deposition samples are listed in Table S3. Of the 43 target compounds, the following 7 were commonly detected in the deposition samples: HCB, $\alpha-\mathrm{HCH}, \quad \gamma-\mathrm{HCH}, p, p^{\prime}-\mathrm{DDT}, p, p^{\prime}$-DDE, $o, p^{\prime}$-DDT, and PCB-28. HCB, $\alpha-\mathrm{HCH}, \gamma-\mathrm{HCH}$, and PCB-28 were found at relatively high concentrations. The average HCB concentration was within the range of $0.003-0.072 \mathrm{ng} \mathrm{L}^{-1}$, which were observed in the United States national parks (Hageman et al., 2006). HCH concentrations were lower than the range of 1.8-5.0 ng L ${ }^{-1}$ obtained in French (Teil et $a l ., 2004$ ) and Atlantic Canadian background sites (Brun et al., 2008). DDTs, including $p, p^{\prime}$-DDT, $p, p^{\prime}$-DDE, and $o, p^{\prime}$-DDT, were found at a low level and also lower than those in Atlantic Canada (Brun et al., 2008).

\section{Effect of Meteorological and Atmospheric Parameters}

Meteorological and atmospheric factors, such as temperature, precipitation, wind direction, and particles, influence the air concentration (Wania et al., 1998; Tian et al., 2009) and deposition (Fernandez et al., 2003) of POPs. Linear regressions of the logarithm of the concentrations of OCP or PCB gas in air versus reciprocal temperature (i.e., $\ln \left(\mathrm{C}_{\text {air }}\right)=\mathrm{m} / \mathrm{T}+\mathrm{b}$ ) are widely used to distinguish temperature-dependent volatilization from various surfaces. A strong temperature dependence of $p, p^{\prime}$-DDE was observed, with a high $\mathrm{R}^{2}$ of 0.66 (Fig. S4), suggesting that this compound is mainly influenced by volatilization. The correlations between $\ln (\mathrm{C})$ and $1 / \mathrm{T}$ of the other compounds were either nonsignificant $(p>0.05)$ or weak $(p<0.05$ and $\mathrm{R}^{2}<0.2$ ), indicating that at LNR, revolatilization from nearby surfaces may not be the major source of most OCPs and PCBs in the atmosphere. The correlation between air concentrations and precipitation was nonsignificant.

The effect of temperature and precipitation on deposition was investigated through linear regression analysis. A significant negative relationship was observed between $\ln \left(\mathrm{C}_{\mathrm{dep}}\right)$ of HCB and temperature (Fig. S5). This relationship is likely related to the tendency of atmospheric HCB to partition into particles during cold seasons given that $\mathrm{HCB}$ concentrations in the atmospheric particles increased in cold seasons (Fig. S6). The correlation between the concentrations of target compounds in the deposition samples and the total suspended particles was nevertheless nonsignificant. For $\alpha$ - and $\gamma-\mathrm{HCH}$ with relatively high water solubilities, significantly high correlation coefficients of 0.97 and 0.92 were observed between precipitation and monthly deposition fluxes, respectively.

\section{Transport and Deposition Trend of OCPs and PCBs}

The movement of airborne pollutants to remote areas entails three essential parameters, namely source emission, transport route, and favorable deposition condition at the receptor site. The following sections discuss the influence of these parameters on pollutant transport and deposition at LNR.

\section{HCHs}

The seasonality of HCHs exhibited a "bimodal" pattern, with higher concentrations in spring and autumn and lower concentrations in summer (Fig. 1). Regarding other sites in the same latitudinal zone (Fig. S1; location details of the Tibetan and central China sites are shown in Table S1), this pattern was observed at the Tibetan Plateau but not at the central China site. Sheng et al. (2013) correlated this bimodal pattern to agricultural input of $\mathrm{HCHs}$ from India and rain scavenging in the rainy season. Zhan et al. (2017) attributed the high $\mathrm{HCH}$ levels in central China during winter to polluted air parcels originating from northern China. PSCF maps of $\alpha$ - and $\gamma-\mathrm{HCH}$ reveal that northern China, Southeast Asia, and the Bay of Bengal are potential sources of HCHs in this study (Fig. S7). Most air parcels arriving at LNR passed through these potential sources from March to September (Fig. S3). The atmospheric concentrations of HCHs were high in March, April, and 

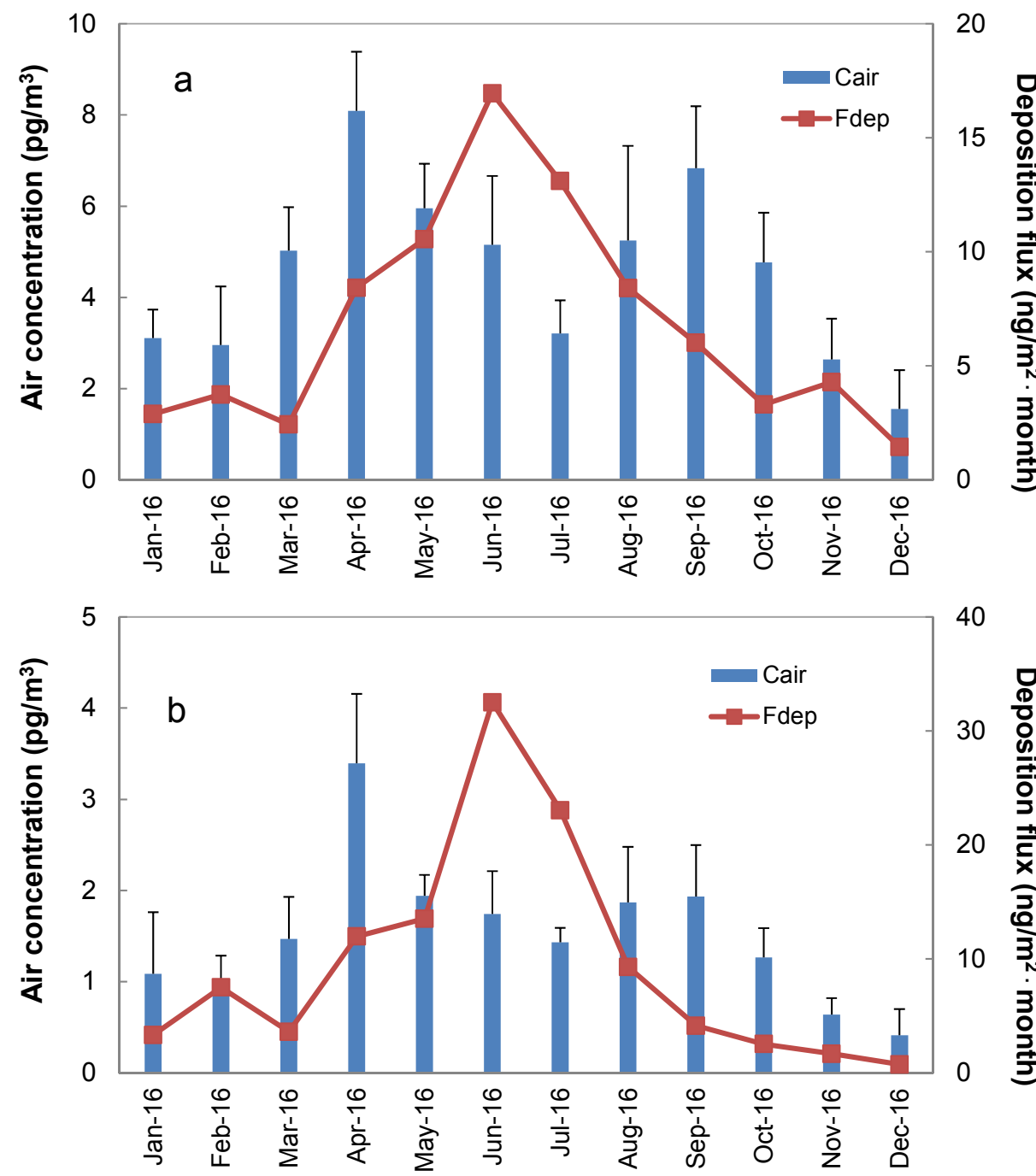

Fig. 1. Seasonality of monthly mean air concentrations and deposition fluxes of (a) $\alpha-\mathrm{HCH}$ and (b) $\gamma-\mathrm{HCH}$.

September and low from May to August, when many trajectories passed through precipitation centers over the Bay of Bengal and the South China Sea (Fig. S3, MayAugust).

For POPs with significant water solubility, such as $\alpha$ and $\gamma-\mathrm{HCH}$, rainfall scavenging in the rainy season is a particularly effective method to remove these compounds from the air. The annual total $\alpha$ - and $\gamma-\mathrm{HCH}$ deposition fluxes were 82 and $114 \mathrm{ng} \mathrm{m}^{-2}$, with atmospheric deposition fluxes from May to August contributing $60 \%$ and $68 \%$, respectively; the relatively low air concentrations during these periods are likely achieved at the expense of high deposition from the air to the ground surface along the transport routes. The water solubility of $\gamma-\mathrm{HCH}\left(7.3 \mathrm{mg} \mathrm{L}^{-1}\right)$ is higher than that of $\alpha-\mathrm{HCH}\left(1.5 \mathrm{mg} \mathrm{L}^{-1}\right)$ (Mackay et al., 2006); hence, wet deposition is more effective for $\gamma-\mathrm{HCH}$ and even significantly influences the $\alpha-/ \gamma-\mathrm{HCH}$ ratio, a source indicator. Between May and July, the average $\alpha-/ \gamma$ $\mathrm{HCH}$ ratio was 2.7 in the atmospheric samples, whereas it was only 0.62 in the deposition samples. For air samples, the average ratio increased from 2.2 in April to 3.1 in May, despite the similarity of the air mass back-trajectories of these two months. These results imply that using isomer ratio indicators to distinguish between sources of relatively highly water-soluble compounds is difficult if the air mass passes through precipitation centers, such as the Bay of Bengal and the South China Sea. For example, the atmospheric $\alpha-\gamma-\mathrm{HCH}$ ratios indicate technical $\mathrm{HCH}$ usage in the mainland of China, Vietnam, and the Kolkata region of India (Chakraborty et al., 2010; Wang et al., 2016) or Lindane use in the China Sea and the Bay of Bengal (Gioia et al., 2012). Intensive precipitation over the sea areas may reduce the Lindane signals in the atmosphere when the air mass arrives at downwind receptors, such as at Tibetan and LNR sites.

\section{$H C B$}

HCB concentration exhibited clear seasonal variations, with elevated concentrations in winter months (Fig. 2), which was also reported in central China (Zhan et al., 2017), the Tibetan Plateau (Sheng et al., 2013), and other observation areas (Wang et al., 2010). Decreasing the atmospheric concentration of HCB is difficult. Comparing the concentrations at the sites shown in Fig. S1, the annual 


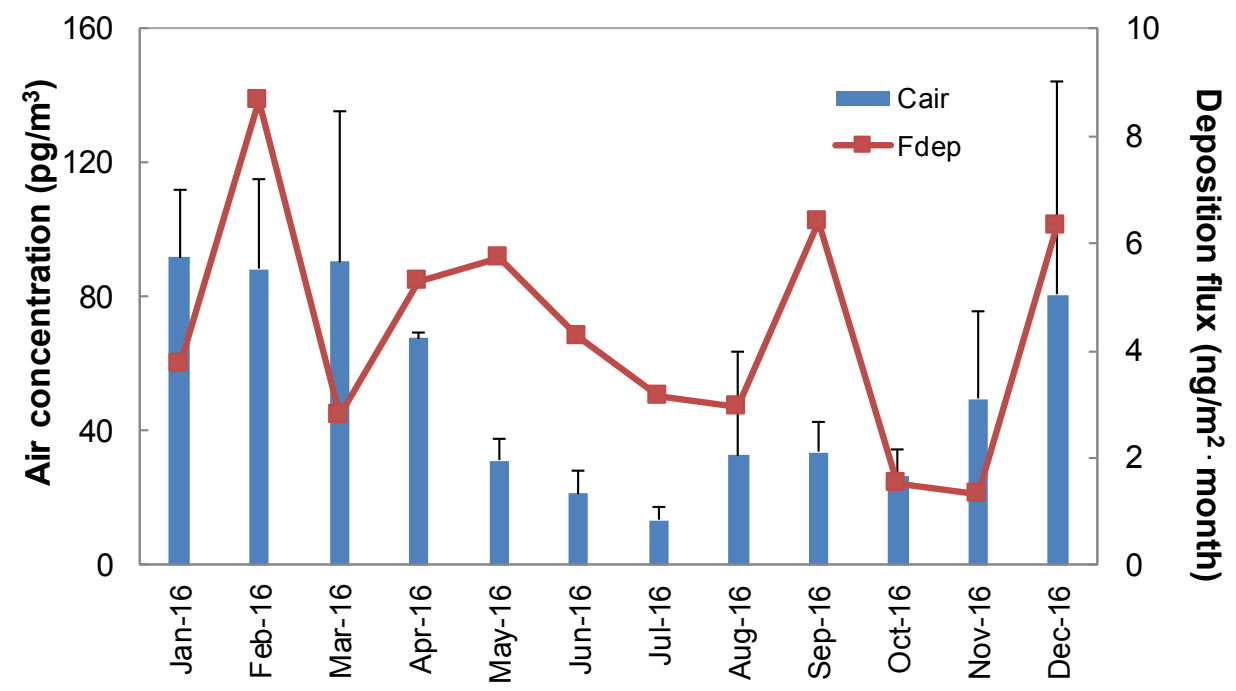

Fig. 2. Seasonality of monthly mean air concentrations and deposition fluxes of HCB.

average concentrations of HCB gradually decreased from east to west, with the highest in central China and the lowest in the Tibetan Plateau (Table S2). This spatial trend suggests that potential sources of HCB are likely located in central and eastern China. The PSCF map of HCB supports this assumption by indicating that the potential sources are widely distributed in southeastern, central, and northern China (Fig. S8). This spatial pattern is similar to that of airborne HCB measured in 2004 (Jaward et al., 2005), suggesting that $\mathrm{HCB}$ concentrations at LNR are still influenced by these source regions, especially in the cold season.

The annual HCB deposition flux of $52.1 \mathrm{ng} \mathrm{m}^{-2}$ was close to those reported at other background sites (Arellano et al., 2015). Elevated HCB deposition fluxes occurred not only in winter but also in summer (Fig. 2). The high fluxes in winter are mainly associated with elevated particleassociated HCB content in the air (Fig. S9). To a less significant extent, elevated gaseous HCB and TSP in the air may be related to high fluxes in winter. Unlike $\mathrm{HCHs}$, $\mathrm{HCB}$ is a volatile compound with low water solubility, meaning that the $\mathrm{HCB}$ dissolution in rainwater during summertime is nonsignificant. The high concentrations in June and August likely reflect the enhanced washout of atmospheric particles during the rainy season.

\section{DDTs}

Seasonality was exhibited by $o, p^{\prime}$-DDT and $p, p^{\prime}$-DDT, with higher concentrations in spring and lower concentrations in winter (Fig. 3), which is quite different from the pattern observed for atmospheric DDTs at sites in the Tibetan Plateau and central China, which exhibited high levels in summer (Sheng et al., 2013; Zhan et al., 2017). The variation of $p, p^{\prime}$-DDE at LNR was significantly correlated with temperature and therefore peaked in July (Fig. S10). By contrast, the highest mean concentrations of $o, p^{\prime}$-DDT and $p, p^{\prime}$-DDT were recorded in April. The potential source regions of $o, p^{\prime}$-DDT are distributed in Southeast Asia, whereas those of $p, p^{\prime}$-DDT include Southeast Asia and eastern China (Fig. S11). The ratio of $o, p^{\prime}$-DDT to $p, p^{\prime}$-DDT, an indicator of DDT sources for technical DDT and dicofol, was $0.98 \pm 0.58$ at LNR; this is consistent with the technical DDT use reported in Vietnam (Zhan et al., 2017) and eastern China (Liu et al., 2009).

Atmospheric fluxes of $o, p^{\prime}$-DDT and $p, p^{\prime}$-DDT peaked in April, accounting for $30 \%$ of the annual total fluxes. The deposition of DDTs with high $\mathrm{K}_{\mathrm{oa}}$ is mainly controlled by atmospheric particles (Yue et al., 2011). The observed deposition fluxes also follow the seasonality of particleassociated DDT concentrations (Fig. S12). In April, the air mass mainly originated from Southeast Asia, before precipitation centers had formed over the oceans (Fig. S3, April); nevertheless, rainfall at LNR started to increase (Fig. S2), which was favorable for atmospheric deposition. By contrast, the low DDT content in the particles and the precipitation amount led to relatively low depositions in cold seasons (Fig. S12); this is despite the air mass occasionally passing through potential source regions in eastern China in cold seasons, bringing about $p, p^{\prime}$-DDT pollution.

\section{$P C B S$}

PCB congeners exhibited similar temporal trends, with high concentrations observed from April to August. The potential sources are presented in the PSCF maps in Fig. S13. The sources of tri-CBs are likely located in lower latitude areas, while those of tetra- and penta-CBs are distributed in central China as well. The map for hex-CBs exclusively displays a few clusters of high-probability cells over central China. Although relevant data on the source regions are limited, the air concentration levels of PCBs in Vietnam (Wang et al., 2016) and India (Chakraborty et al., 2013) have been reported to be higher than those in other Asian countries. The high atmospheric PCB concentrations over the South China Sea and the Bay of Bengal (Gioia et al., 2012) could also contribute to PCB transport. PCB-28 was the only $\mathrm{PCB}$ congener detected in all deposition samples. The trends in monthly deposition fluxes were similar 

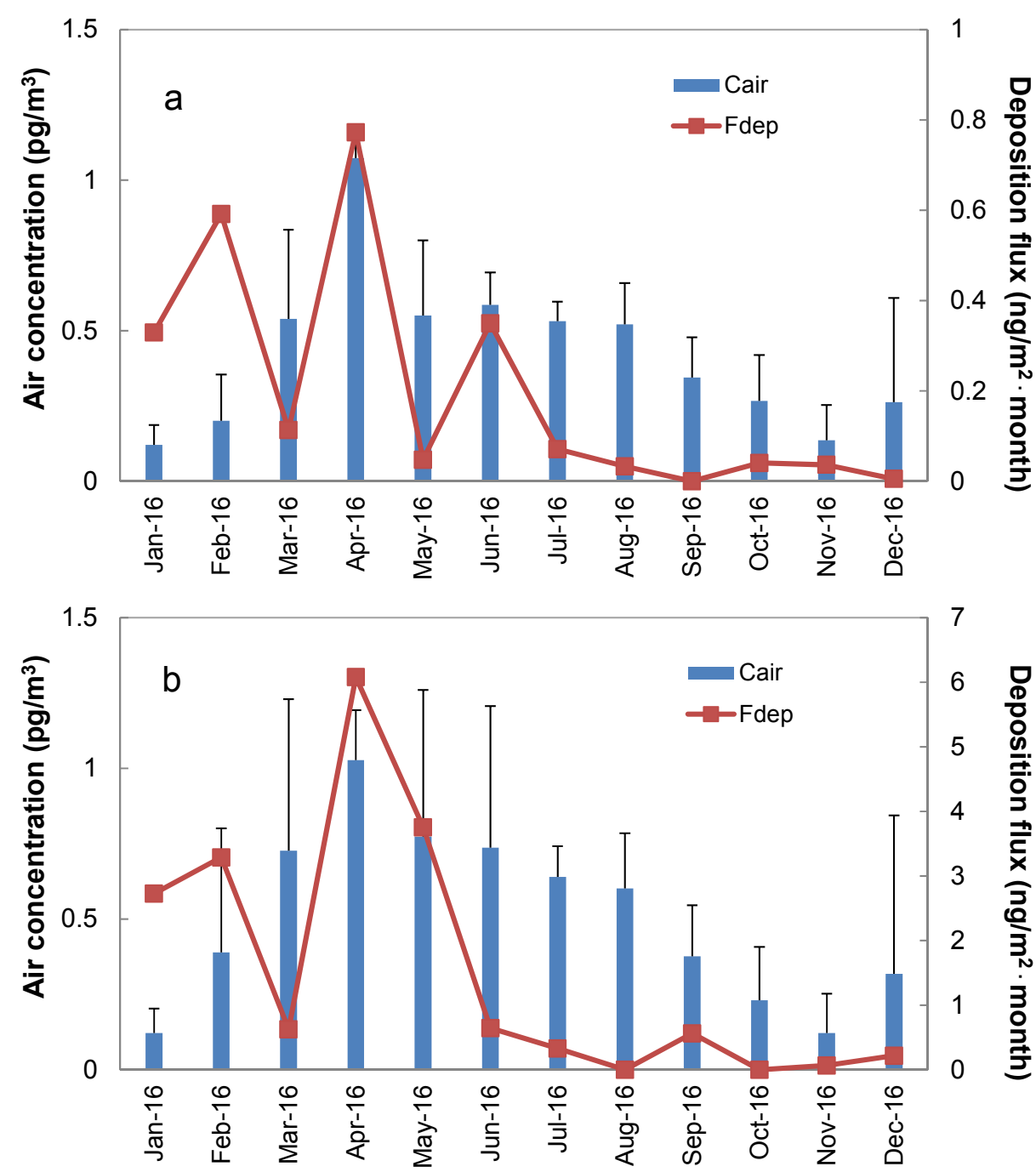

Fig. 3. Seasonality of monthly mean air concentrations and deposition fluxes of (a) $o, p^{\prime}$-DDT and (b) $p, p^{\prime}$-DDT.

to those of air concentration (Fig. S14): The deposition flux was high in the rainy season, when air masses mainly arrived from the west.

\section{Comparison of Measured and Predicted Deposition Fluxes}

Fig. 4 compares the measured and predicted deposition fluxes at LNR. The similarity between the measured and predicted seasonal trends suggests a strong link between atmospheric input and deposition. The measured deposition fluxes were generally higher than the predicted equilibrium fluxes, except for compounds whose concentrations were close to the MDL, such as $o, p^{\prime}$-DDT. Numerous studies have suggested that fog, clouds, and snow at high altitudes can scavenge organic pollutants from the atmosphere, often more efficiently than rain (Jakobi et al., 2015). At LNR, our sampling site is a low-latitude site characterized by foggy weather. We suspect that the fog may induce higher deposition. In a previous numerical simulation, the $\alpha-\mathrm{HCH}$ sink in southwestern China was found to be related to atmospheric transport and strong deposition in the rainy season (Xu et al., 2013). The measured deposition fluxes at LNR being higher than predicted indicates that deposition input in the surrounding areas might be even higher than previously estimated.

\section{CONCLUSIONS}

The atmospheric transport and deposition of OCPs and PCBs at LNR, a nature reserve in southwestern China, were investigated. Governments in Asia have prohibited or restricted POPs, as stipulated in the Stockholm Convention; consequently, atmospheric concentrations of POPs, aside from $\mathrm{HCB}$, have exhibited a declining trend. Nevertheless, temporal shifts in the wind field can cause pollutants to be transported to LNR from neighboring regions, such as mainland China and South or Southeast Asia. Wet deposition, including that in the dissolved and particulate phases, acts as an effective transfer mechanism. The atmospheric transport and deposition of compounds with relatively high water solubility, such as HCHs, in the rainy season, when air masses mainly originate in western source areas, contributed to a significant proportion of the air input, and the low atmospheric levels of pollution at LNR are likely achieved at the expense of high surface input along the 

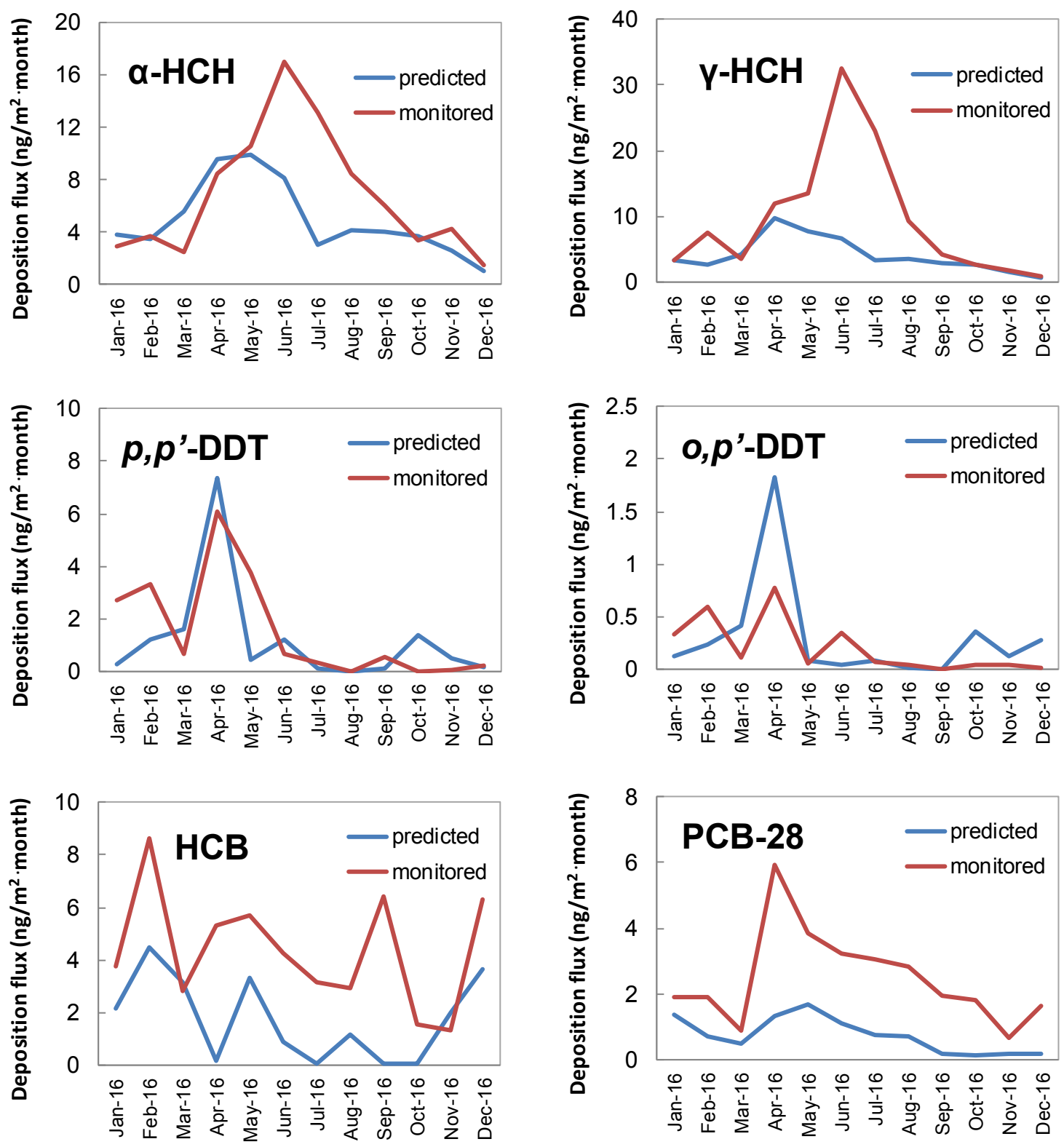

Fig. 4. Measured and predicted deposition fluxes at LNR.

transport routes. Washouts of particles via precipitation also influenced the total deposition of other compounds. The deposition trends of HCB and DDTs followed the temporal variations of their particle-associated content, with the highest deposition fluxes occurring in winter and April, respectively. Except for DDTs, the measured deposition fluxes were higher than the predicted equilibrium fluxes for all compounds, which may be related to the foggy weather at LNR.

\section{ACKNOWLEDGMENTS}

The authors appreciate the financial support from the National Natural Science Foundation of China (NSFC) (41403106, 414300417, 41673133, 71403118, and 41101495) and National Key R\&D Program of China (ATMSYC, 2017YFC0212000). Author contributions: conceptualization:
Jiayi Zhou and Yue $\mathrm{Xu}$; sample and data analysis: Jiayi Zhou, Libin Liu, and Xin $\mathrm{Xu}$; sample collection: Yongfu $\mathrm{Yu}$ and Yang Li; writing, review, and editing: Haiyan Zhang and Yue $\mathrm{Xu}$. This manuscript was edited by Wallace Academic Editing.

\section{SUPPLEMENTARY MATERIAL}

Supplementary data associated with this article can be found in the online version at http://www.aaqr.org.

\section{REFERENCES}

Arellano, L., Fernandez, P., Fonts, R., Rose, N.L., Nickus, U., Thies, H., Stuchlik, E., Camarero, L., Catalan, J. and Grimalt, J.O. (2015). Increasing and decreasing trends of the atmospheric deposition of organochlorine 
compounds in European remote areas during the last decade. Atmos. Chem. Phys. 15: 6069-6085.

Bergknut, M., Laudon, H., Jansson, S., Larsson, A., Gocht, T. and Wiberg, K. (2011). Atmospheric deposition, retention, and stream export of dioxins and PCBs in a pristine boreal catchment. Environ. Pollut. 159: 15921598.

Bidleman, T.F., Laudon, H., Nygren, O., Svanberg, S. and Tysklind, M. (2017). Chlorinated pesticides and natural brominated anisoles in air at three northern Baltic stations. Environ. Pollut. 225: 381-389.

Bossi, R., Vorkamp, K. and Skov, H. (2016). Concentrations of organochlorine pesticides, polybrominated diphenyl ethers and perfluorinated compounds in the atmosphere of north Greenland. Environ. Pollut. 217: 4-10.

Bruckmann, P., Hiester, E., Klees, M. and Zetzsch, C. (2013). Trends of PCDD/F and PCB concentrations and depositions in ambient air in northwestern Germany. Chemosphere 93: 1471-1478.

Brun, G.L., MacDonald, R.M., Verge, J. and Aubé, J. (2008). Long-term atmospheric deposition of currentuse and banned pesticides in Atlantic Canada; 19802000. Chemosphere 71: 314-327.

Carrera, G., Fernández, P., Grimalt, J.O., Ventura, M., Camarero, L., Catalan, J., Nickus, U., Thies, H. and Psenner, R. (2002). Atmospheric deposition of organochlorine compounds to remote high mountain lakes of Europe. Environ. Sci. Technol. 36: 2581-2588.

Chakraborty, P., Zhang, G., Li, J., Xu, Y., Liu, X., Tanabe, S. and Jones, K.C. (2010). Selected organochlorine pesticides in the atmosphere of major Indian cities: Levels, regional versus local variations, and sources. Environ. Sci. Technol. 44: 8038-8043.

Chakraborty, P., Zhang, G., Eckhardt, S., Li, J., Breivik, K., Lam, P.K.S., Tanabe, S. and Jones, K.C. (2013). Atmospheric polychlorinated biphenyls in Indian cities: Levels, emission sources and toxicity equivalents. Environ. Pollut. 182: 283-290.

Cui, S., Fu, Q., Ma, W.L., Song, W.W., Liu, L.Y. and Li, Y.F. (2015). A preliminary compilation and evaluation of a comprehensive emission inventory for polychlorinated biphenyls in China. Sci. Total Environ. 533: 247-255.

Fernandez, P., Carrera, G., Grimalt, J.O., Ventura, M., Camarero, L., Catalan, J., Nickus, U., Thies, H. and Psenner, R. (2003). Factors governing the atmospheric deposition of polycyclic aromatic hydrocarbons to remote areas. Environ. Sci. Technol. 37: 3261-3267.

Gioia, R., Li, J., Schuster, J., Zhang, Y.L., Zhang, G., Li, X.D., Spiro, B., Bhatia, R.S., Dachs, J. and Jones, K.C. (2012). Factors affecting the occurrence and transport of atmospheric organochlorines in the China Sea and the northern Indian and South east Atlantic oceans. Environ. Sci. Technol. 46: 10012-10021.

Gioia, R., Offenberg, J.H., Gigliotti, C.L., Totten, L.A., Du, S. and Eisenreich, S.J. (2005). Atmospheric concentrations and deposition of organochlorine pesticides in the US Mid-Atlantic region. Atmos. Environ. 39: 2309-2322.

Gong, P., Wang, X., Sheng, J., Wang, H., Yuan, X., He, Y., Qian, Y. and Yao, T. (2017). Seasonal variations and sources of atmospheric polycyclic aromatic hydrocarbons and organochlorine compounds in a high-altitude city: Evidence from four-year observations. Environ. Pollut. 233: 1188-1197.

Guo, L.C., Bao, L.J., Li, S.M., Tao, S. and Zeng, E.Y. (2017). Evaluating the effectiveness of pollution control measures via the occurrence of DDTs and HCHs in wet deposition of an urban center, China. Environ. Pollut. 223: $170-177$.

Hafner, W.D. and Hites, R.A. (2003). Potential sources of pesticides, PCBs, and PAHs to the atmosphere of the Great Lakes. Environ. Sci. Technol. 37: 3764-3773.

Hageman, K.J., Simonich, S.L., Campbell, D.H., Wilson, G.R. and Landers, D.H. (2006). Atmospheric deposition of current-use and historic-use pesticides in snow at national parks in the western United States. Environ. Sci. Technol. 40: 3174-3180.

Hillery, B.R., Simcik, M.F., Basu, I., Hoff, R.M., Strachan, W.M.J., Burniston, D., Chan, C.H., Brice, K.A., Sweet, C.W. and Hites, R.A. (1998). Atmospheric deposition of toxic pollutants to the Great Lakes as measured by the integrated atmospheric deposition network. Environ. Sci. Technol. 32: 2216-2221.

Hoff, R.M., Strachan, W.M.J., Sweet, C.W., Chan, C.H., Shackleton, M., Bidleman, T.F., Brice, K.A., Burniston, D.A., Cussion, S., Gatz, D.F., Harlin, K. and Schroeder, W.H. (1996). Atmospheric deposition of toxic chemicals to the Great Lakes: A review of data through 1994. Atmos. Environ. 30: 3505-3527.

Hoh, E. and Hites, R.A. (2004). Sources of toxaphene and other organochlorine pesticides in North America as determined by air measurements and potential source contribution function analyses. Environ. Sci. Technol. 38: 4187-4194.

Huang, Y., Li, J., Xu, Y., Xu, W., Cheng, Z., Liu, J., Wang, Y., Tian, C., Luo, C. and Zhang, G. (2014). Polychlorinated biphenyls (PCBs) and hexachlorobenzene (HCB) in the equatorial Indian Ocean: Temporal trend, continental outflow and air-water exchange. Mar. Pollut. Bull. 80: 194-199.

Hung, H., Katsoyiannis, A.A., Brorström-Lundén, E., Olafsdottir, K., Aas, W., Breivik, K., Bohlin-Nizzetto, P., Sigurdsson, A., Hakola, H., Bossi, R., Skov, H., Sverko, E., Barresi, E., Fellin, P. and Wilson, S. (2016). Temporal trends of persistent organic pollutants (POPs) in Arctic air: 20 years of monitoring under the Arctic Monitoring and Assessment Programme (AMAP). Environ. Pollut. 217: 52-61.

Jakobi, G., Kirchner, M., Henkelmann, B., Körner, W., Offenthaler, I., Moche, W., Weiss, P., Schaub, M. and Schramm, K.W. (2015). Atmospheric bulk deposition measurements of organochlorine pesticides at three alpine summits. Atmos. Environ. 101: 158-165.

Jaward, T.M., Zhang, G., Nam, J.J., Sweetman, A.J., Obbard, J.P., Kobara, Y. and Jones, K.C. (2005). Passive air sampling of polychlorinated biphenyls, organochlorine compounds, and polybrominated diphenyl ethers across Asia. Environ. Sci. Technol. 39: 8638-8645.

Kirchner, M., Jakobi, G., Körner, W., Levy, W., Moche, 
W., Niedermoser, B., Schaub, M., Ries, L., Weiss, P., Antritter, F., Fischer, N., Henkelmann, B. and Schramm, K.W. (2016). Ambient air levels of organochlorine pesticides at three high alpine monitoring stations: Trends and dependencies on geographical origin. Aerosol Air Qual. Res. 16: 738-751.

Liu, F., Xu, Y., Liu, J., Liu, D., Li, J., Zhang, G., Li, X., Zou, S. and Lai, S. (2013). Atmospheric deposition of polycyclic aromatic hydrocarbons (PAHs) to a coastal site of Hong Kong, South China. Atmos. Environ. 69: 265-272.

Liu, X., Zhang, G., Li, J., Yu, L.L., Xu, Y., Li, X.D., Kobara, Y. and Jones, K.C. (2009). Seasonal patterns and current sources of DDTs, chlordanes, hexachlorobenzene, and endosulfan in the atmosphere of 37 Chinese cities. Environ. Sci. Technol. 43: 1316-1321.

Mackay, D., Shiu, W.Y., Ma, K.C. and Lee, S.C. (2006). Handbook of physical-chemical properties and environmental fate for organic chemicals, 2nd ed. CRC Press, Boca Raton.

Melymuk, L., Robson, M., Diamond, M.L., Bradley, L.E. and Backus, S. (2011). Wet deposition loadings of organic contaminants to Lake Ontario: Assessing the influence of precipitation from urban and rural sites. Atmos. Environ. 45: 5042-5049.

Miller, S.M., Green, M.L., DePinto, J.V. and Hornbuckle, K.C. (2001). Results from the Lake Michigan mass balance study: Concentrations and fluxes of atmospheric polychlorinated biphenyls and trans-nonachlor. Environ. Sci. Technol. 35: 278-285.

SEPAC (The state council of the People's Republic of China) (2007). National implementation plan for the Stockholm Convention on persistent organic pollutants. State Environmental Protection Administration of China.

Sheng, J.J., Wang, X.P., Gong, P., Joswiak, D.R., Tian, L.D., Yao, T.D. and Jones, K.C. (2013). Monsoon-driven transport of organochlorine pesticides and polychlorinated biphenyls to the Tibetan Plateau: Three year atmospheric monitoring study. Environ. Sci. Technol. 47: 3199-3208.

Teil, M.J., Blanchard, M. and Chevreuil, M. (2004). Atmospheric deposition of organochlorines (PCBs and pesticides) in northern France. Chemosphere 55: 501514.

Tian, C., Ma, J., Liu, L., Jia, H., Xu, D. and Li, Y.F. (2009). A modeling assessment of association between East Asian summer monsoon and fate/outflow of $\alpha-\mathrm{HCH}$ in Northeast Asia. Atmos. Environ. 43: 3891-3901.

Van Ry, D.A., Gigliotti, C.L., Glenn, T.R., Nelson, E.D., Totten, L.A. and Eisenreich, S.J. (2002). Wet deposition of polychlorinated biphenyls in urban and background areas of the mid-Atlantic states. Environ. Sci. Technol. 36: 3201-3209.

Wang, B., Clemens, S.C. and Liu, P. (2003). Contrasting the Indian and East Asian monsoons: Implications on geologic timescales. Mar. Geol. 201: 5-21.

Wang, G., Lu, Y., Han, J., Luo, W., Shi, Y., Wang, T. and Sun, Y. (2010). Hexachlorobenzene sources, levels and human exposure in the environment of China. Environ. Int. 36: 122-130.

Wang, T., Lu, Y., Zhang, H. and Shi, Y. (2005). Contamination of persistent organic pollutants (POPs) and relevant management in China. Environ. Int. 31: 813-821.

Wang, W., Wang, Y., Zhang, R., Wang, S., Wei, C., Chaemfa, C., Li, J., Zhang, G. and Yu, K. (2016). Seasonal characteristics and current sources of OCPs and PCBs and enantiomeric signatures of chiral OCPs in the atmosphere of Vietnam. Sci. Total Environ. 542: 777-786.

Wania, F., Haugen, J.E., Lei, Y.D. and Mackay, D. (1998). Temperature dependence of atmospheric concentrations of semivolatile organic compounds. Environ. Sci. Technol. 32: 1013-1021.

Wong, H.L., Giesy, J.P. and Lam, P.K.S. (2004). Atmospheric deposition and fluxes of organochlorine pesticides and coplanar polychlorinated biphenyls in aquatic environments of Hong Kong, China. Environ. Sci. Technol. 38: 6513-6521.

Xu, Y., Tian, C., Zhang, G., Ming, L., Wang, Y., Chen, Y., Tang, J., Li, J. and Luo, C. (2013). Influence of monsoon system on alpha-HCH fate in Asia: A model study from 1948 to 2008. J. Geophys. Res. 118: 67646770 .

Yang, G., Ma, L., Xu, D., Liu, L., Jia, H., Chen, Y., Zhang, Y. and Chai, Z. (2012). Temporal trends of polychlorinated biphenyls in precipitation in Beijing, China. Atmos. Environ. 56: 222-227.

Yue, Q., Zhang, K., Zhang, B.Z., Li, S.M. and Zeng, E.Y. (2011). Occurrence, phase distribution and depositional intensity of dichlorodiphenyltrichloroethane (DDT) and its metabolites in air and precipitation of the Pearl River Delta, China. Chemosphere 84: 446-451.

Zhan, L., Lin, T., Wang, Z., Cheng, Z., Zhang, G., Lyu, X. and Cheng, H. (2017). Occurrence and air-soil exchange of organochlorine pesticides and polychlorinated biphenyls at a CAWNET background site in central China: Implications for influencing factors and fate. Chemosphere 186: 475-487.

Zheng, Q., Nizzetto, L., Mulder, M., Sáňka, O., Lammel, G., Li, J., Bing, H.J., Liu, X., Jiang, Y.S. and Zhang, G. (2014). Does an analysis of polychlorinated biphenyl (PCB) distribution in mountain soils across China reveal a latitudinal fractionation paradox? Environ. Pollut. 195: $115-122$. 